\title{
Effects of Silica Filler and Diluent on Material Properties and Reliability of Nonconductive Pastes (NCPs) for Flip-Chip Applications
}

Kyung-Woon Jang, Woon-Seong Kwon, Myung-Jin Yim, Associate Member, IEEE, and Kyung-Wook Paik, Member, IEEE

\begin{abstract}
In this paper, thermomechanical and rheological properties of nonconductive pastes (NCPs) depending on silica filler contents and diluent contents were investigated. And then, thermal cycling (T/C) reliability of flip chip assembly using selected NCPs was verified.

As the silica filler content increased, thermomechanical properties of NCPs were changed. The higher the silica filler content was added, glass transition temperature $\left(T_{g}\right)$ and storage modulus at room temperature became higher while coefficient of thermal expansion (CTE) decreased. On the other hand, rheological properties of NCPs were significantly affected by diluent content. As the diluent content increased, viscosity of NCP decreased and thixotropic index increased. However, the addition of diluent deteriorated thermomechanical properties such as modulus, CTE, and $T_{g}$.

Based on these results, three candidates of NCPs with various silica filler and diluent contents were selected and used as adhesives for reliability test of flip chip assemblies. T/C reliability test was performed by measuring changes of NCP bump connection resistance. Results showed that flip chip assembly using NCP with lower CTE and higher modulus exhibited better T/C reliability behavior because of reduced shear strain in NCP adhesive layer.
\end{abstract}

Index Terms-Diluent, filler, flip chip, nonconductive paste (NCP), reliability, stud bump, thermal cycling (T/C).

\section{INTRODUCTION}

A S ELECTRONIC packaging technology trends move toward lower cost, fine pitch, higher electrical performance and better reliability, flip chip technology gains popularity as one of the best chip packaging candidates to meet these trends.

Although flip chip assembly using solder balls is in the main stream of flip chip technology, flip chip assemblies using polymer conductive adhesives such as isotropic conductive adhesives (ICAs), anisotropic conductive films (ACFs), and nonconductive pastes (NCPs) have been under development because of their potential advantages compared with solder

Manuscript received March 9, 2003; revised January 26, 2004. This work was recommended for publication by Associate Editor C. C. Lee upon evaluation of the reviewers' comments.

K.-W. Jang, W.-S. Kwon, and K.-W. Paik are with the Department of Materials Science and Engineering, Korean Advanced Institute of Science and Technology (KAIST), Daejeon 305-701, Korea (e-mail: amiha@kaist.ac.kr; wskwon@kaist.ac.kr; kwpaik@kaist.ac.kr).

M.-J. Yim is with the ACA/F Department, Telephus, Inc., Daejeon 305-343, Korea (e-mail: mjyim@telephus.com).

Digital Object Identifier 10.1109/TCAPT.2004.832054 flip chip assemblies such as lower processing temperature, lower cost due to fewer assembly processing steps, and cheaper bumping method, and green process (no lead, no flux, and no cleaning solvent).

Among these conductive adhesive flip chip technologies, flip chip with NCPs and gold stud bumps is one of the promising method for certain applications. Therefore, it is necessary to investigate thermomechanical properties and rheology of NCPs. The thermomechanical properties such as modulus, CTE, and $\mathrm{T}_{\mathrm{g}}$ are important for good flip chip assembly reliability, and rheological properties such as viscosity and thixotropy are important for good NCPs dispensability.

It is previously observed that adhesives flip chip on organic substrates fails during the thermal cycling test mainly due to high CTE of adhesive layer [1]. Therefore, silica $\left(\mathrm{SiO}_{2}\right)$ fillers are added to reduce CTE for good T/C reliability. However, NCPs viscosity increases as silica filler content increases resulting in a poor dispensability. To solve dispensability problem, diluent is added.

In this study, effects of silica fillers and diluent on NCP properties are investigated. Finally, the relationship between thermomechanical properties of NCPs and T/C reliability of NCP flip chip on organic substrates will be discussed.

\section{EXPERIMENT}

\section{A. NCP Materials}

NCPs were composed of bisphenol-A type liquid epoxy, twomethyl imidazole latent curing agent, silica filler, and diluent. The liquid epoxy was from Aldrich Chemical Company, Inc. and the silica filler was from Kojundo Chemical Laboratory Co., Ltd. in Japan. The diluent was from Miwon Commercial Co., Ltd. in Korea. The silica filler was average $0.8 \mu \mathrm{m}$ in diameter. No pretreatment for silica filler was performed. Various amounts ( $0 \mathrm{wt} \%, 10 \mathrm{wt} \%, 20 \mathrm{wt} \%$, and $30 \mathrm{wt} \%$ ) of silica filler were mixed with liquid epoxy to investigate effects of silica filler on NCP material properties. And, to investigate effects of diluent on NCP material properties, various amounts $(2.1 \mathrm{wt} \%$, $4.2 \mathrm{wt} \%, 6.2 \mathrm{wt} \%$, and $8.0 \mathrm{wt} \%$ ) of diluent were also added at the same silica filler content. Fig. 1 shows the chemical structure of HDGE (1,6-Hexanediol diglycidyl ether) diluent. NCPs were mixed for $2 \mathrm{~min}$ for uniform dispersion in epoxy matrix 


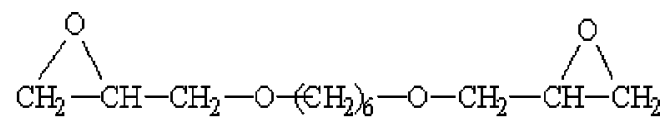

Fig. 1. Chemical structure of 1,6-Hexanediol diglycidyl ether (HDGE) diluent.

and degassed for $30 \mathrm{~s}$ to remove pores and bubbles out. The differential scanning calorimeter (DSC) was performed to investigate curing behaviors of NCPs. Cured NCPs were prepared by placing in a suitable mold in an oven at $165^{\circ} \mathrm{C}$ for about $30 \mathrm{~min}$ and grinding into proper size for the thermomechanical characterization such as dynamic mechanical analysis (DMA), and thermomechanical analysis (TMA). Rheological behaviors of NCPs were also investigated using a rheometer and viscometer.

\section{B. Characterization}

1) Differential Scanning Calorimeter (DSC): DSC experiments were performed to determine curing profiles of NCP materials with various filler content and diluent content. Aluminum pans containing $5 \sim 7 \mathrm{mg} \mathrm{NCP}$ were heated from $50^{\circ} \mathrm{C}$ to $200^{\circ} \mathrm{C}$ at a heating rate of $10^{\circ} \mathrm{C} / \mathrm{min}$ under nitrogen environment.

2) Dynamic Mechanical Analysis (DMA): The storage modulus and loss tangent $(\tan \delta)$ of cured NCPs were measured using cured NCPs grinded into cubes with dimension of about $2 \times 5 \times 20 \mathrm{~mm}$. The measurement was performed by a threepoint bending method under $1-\mathrm{Hz}$ sinusoidal strain loading with heating from 0 to $300{ }^{\circ} \mathrm{C}$ using $10^{\circ} \mathrm{C} / \mathrm{min}$ heating rate. Storage modulus $\left(E^{\prime}\right)$ and loss tangent were obtained.

3) Thermomechanical Analysis (TMA): CTEs of cured NCPs with various silica filler content and diluent content were measured using TMA. $2 \mathrm{~mm}$ thickness and $10 \mathrm{~mm}$ diameter samples were heated from 25 to $200{ }^{\circ} \mathrm{C}$ at a heating rate of $5{ }^{\circ} \mathrm{C} / \mathrm{min}$, and detected dimensional change with $100-\mathrm{N}$ compression load. Coefficient of thermal expansions (CTEs) were measured.

4) Rheology Analysis: Rheological properties of NCPs were measured using a rheometer. NCP mixture was sheared between a cone and a plate at shear rates from 0 to $100 \mathrm{sec}^{-1}$ for $2 \mathrm{~min}$. After shear rate came to a maximum value, shearing force was removed. Also, thixotropic index (=viscosity at $0.5 \mathrm{rpm} / \mathrm{vis}-$ cosity at $5 \mathrm{rpm}$ ) was obtained using a viscometer.

\section{Stud Bump Formation}

It is necessary to form bumps on I/O pads of chips to be interconnected on substrates using NCPs. Gold stud bumps were formed on each I/O pads of chips. Total 34 peripheral bumps were formed on dog-bone patterns of chips.

\section{Flip Chip Assembly Using NCPs}

Substrates used for flip chip assembly were $1.2 \mathrm{~mm}$ thick PCB (FR-4 substrate). The specifications of test chips and test boards were summarized in Table I. There are three process steps for NCP flip chip assembly on an organic substrate. First, gold stud bumps on chips and I/O pads on test substrates were aligned. And then NCPs were dispensed on a substrate to interconnect chips. Finally, bonding pressure of $130 \mathrm{~N}$ was applied to bond a chip on a substrate at $180{ }^{\circ} \mathrm{C}$ for $70 \mathrm{~s}$. As a result, chips
TABLE I

SPECIFICATIONS OF TEST CHIPS AND ORGANIC SUBSTRATES FOR NCP FLIP CHIP ASSEMBLY

\begin{tabular}{cc}
\hline Specification & Substrate \\
\hline Material & FR-4 \\
Size $(\mathrm{mm} \times \mathrm{mm})$ & $34 \times 37$ \\
Final metallization & Cu/Ni/Au \\
\hline Specification & Test IC \\
\hline Size $($ mm $\times$ mm $)$ & $14.7 \times 8.6$ \\
I/Os & 32 \\
Pitch $(\mu \mathrm{m})$ & 800 \\
& \\
\hline Pad size $(\mu \mathrm{m}$ diameter $)$ & 400 \\
& \\
\hline
\end{tabular}

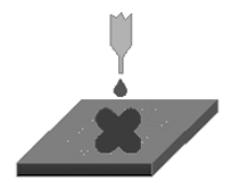

Paste dispensing

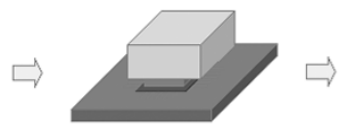

Flip Chip Bonding

(a)

(b)

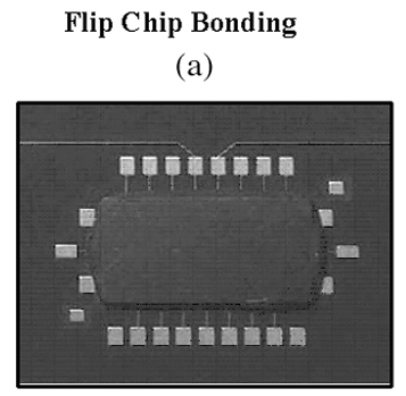

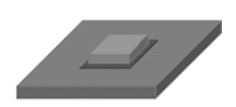

Completed
Fig. 2. Schematic view of: (a) flip chip bonding process using NCPs and (b) real image of assembled flip chip.

were electrically interconnected between PCB pads and stud bumps due to mechanical contact. Fig. 2 shows flip chip bonding process using NCPs and the appearance of a chip bonded on an organic board.

\section{E. Reliability Test}

$\mathrm{T} / \mathrm{C}$ reliability test was performed for three selected NCPs. To investigate the effect of silica filler, no silica filler added NCPs and $30 \mathrm{wt} \%$ silica filler added NCPs were used. In addition, to investigate effect of diluent on $\mathrm{T} / \mathrm{C}$ reliability, no diluent contained NCPs and $4.2 \mathrm{wt} \%$ diluent contained NCPs (with same silica filler content, $30 \mathrm{wt} \%$ ) were used. Compositions of three NCPs (NCP-A, NCP-B, and NCP-C) were summarized in Table II. To investigate the reliability of NCP flip chips on organic substrates, analysis of the contact resistance of a single 
TABLE II

SUMMARY OF COMPOSITION OF NCPS SELECTED FOR RELIABILITY TEST

\begin{tabular}{ccccc}
\hline NCP materials & Epoxy $(\mathrm{g})$ & Hardener $(\mathrm{g})$ & Silica filler $(\mathrm{wt} \%) 30$ & Diluent $(\mathrm{wt} \%)$ \\
\hline NCP-A & 10 & 5 & - & - \\
NCP-B & 10 & 5 & 30 & - \\
NCP-C & 10 & 5 & 30 & 4.2 \\
\hline
\end{tabular}

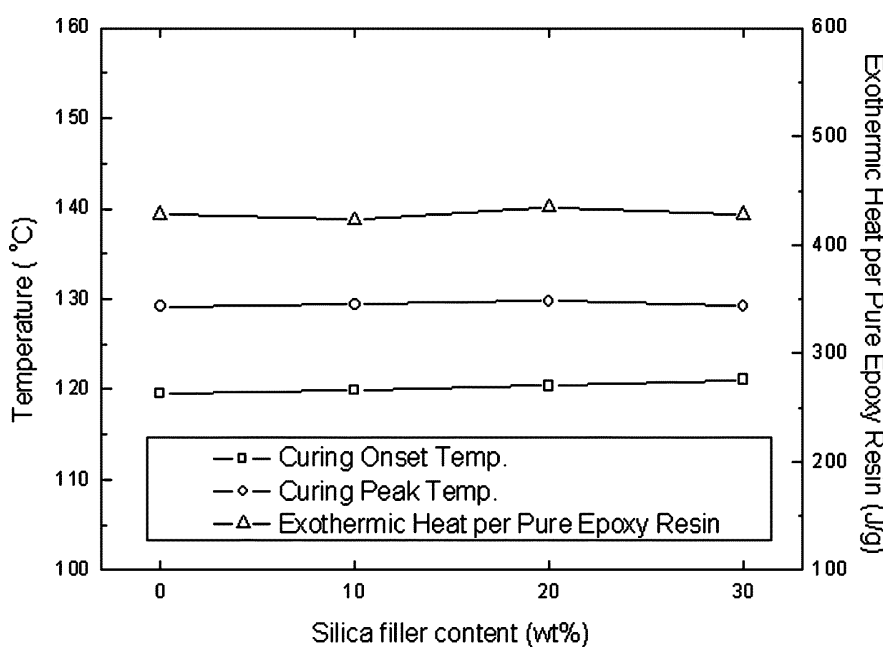

Fig. 3. DSC result as a function of added silica filler content.

interconnect is important. Failure was defined when connection resistance increased more than 100\%. Typical $\mathrm{Pb} / 63 \mathrm{Sn}$ solder reflow process was carried out two times before $-55^{\circ} \mathrm{C}(15$ $\min ) \sim 125^{\circ} \mathrm{C}(15 \mathrm{~min})$ thermal cycling reliability test.

\section{RESULTS AND DISCUSSION}

\section{A. Effects of Silica Fillers on NCP Properties}

To improve thermomechanical properties of NCP composites, silica fillers were added. In this chapter, effects of silica fillers on NCP material properties such as CTE, modulus, $\mathrm{T}_{\mathrm{g}}$, and viscosity, etc. were described.

1) DSC Result: Fig. 3 shows summary of DSC results as a function of silica filler content. Addition of silica filler content slightly increased the curing onset and peak temperature, which was reported elsewhere [1]. However, exothermic amount of heat per actual epoxy resin was almost the same.

2) DMA Result: Fig. 4 shows curves of the storage modulus $\left(E^{\prime}\right)$ and loss tangent $(\tan \delta)$ of NCPs with various silica filler content at various temperature. The storage modulus of cured NCPs increased as silica filler content increased at room temperature. The glass transition temperature $\left(\mathrm{T}_{\mathrm{g}}^{\mathrm{DMA}}\right)$, characterized by the maximum value of loss tangent $(\tan \delta)$, increased as silica filler content increased. These behaviors are due to the increase of polymer/filler interaction in NCPs. If silica filler content increases continuously, the internal friction due to the increase of polymer/filler interface will rise quickly, resulting in hindering the movement of the polymer molecules. This increase in friction made $T_{g}$ higher as silica filler content increased [2]. This "stiffening effect" is presumably due to large specific surface area of silica fillers.

For underfill materials in case of solder flip chip assembly, high modulus is needed to effectively redistribute the solder

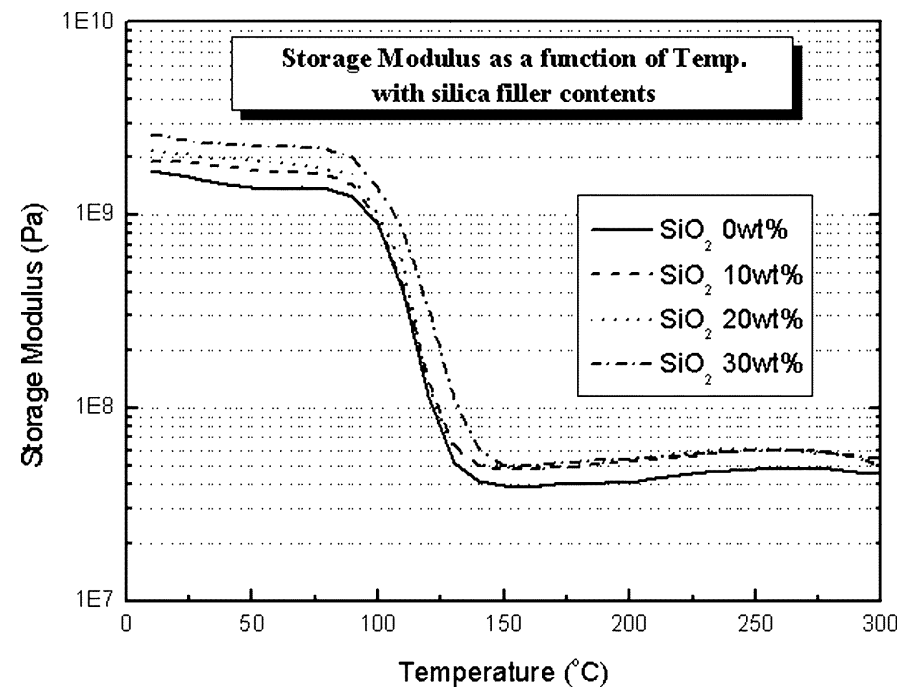

(a)

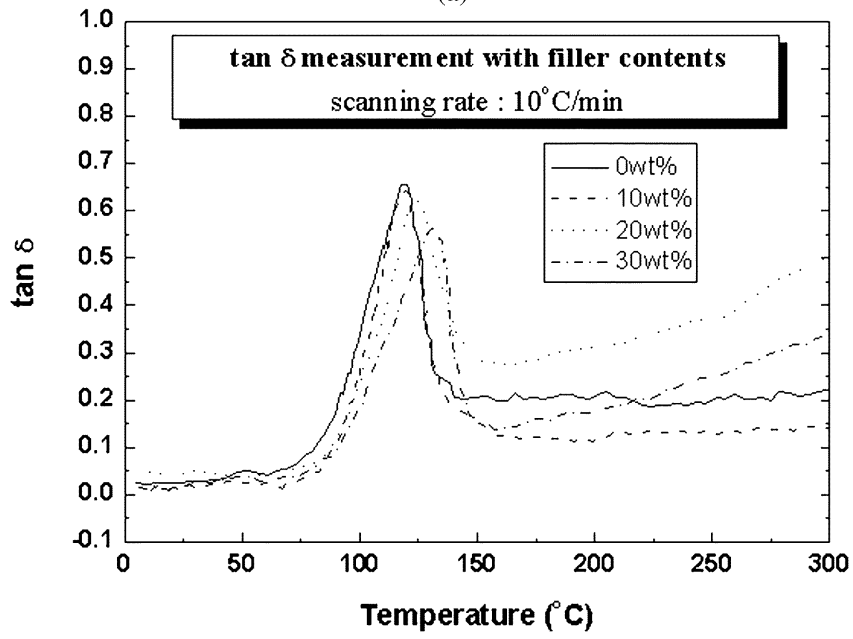

(b)

Fig. 4. (a) Storage modulus curve and (b) $\tan \delta$ curve of NCPs with $0 \sim 30$ wt $\%$ silica filler content.

joints stress to the chip and substrate through the assembly warpage [3]. Similarly, since NCP materials assembled on an organic substrate function as both underfill and die adhesive, higher modulus by adding high content of silica filler is needed. Therefore, higher content of silica filler is preferred, unless the viscosity of NCP is too high to be used during the dispensing process.

3) TMA Result: Fig. 5 shows CTE values of NCPs with various silica filler content measured in TMA. Higher silica filler content causes the decrease of CTE due to stiffening effect of composite materials with larger interface area between silica filler and epoxy resin as discussed in DMA results. The CTE of NCPs below $\mathrm{T}_{\mathrm{g}}$ defined as $\alpha 1$ and the CTE above $\mathrm{T}_{\mathrm{g}}$ defined as $\alpha 2$, are important parameters in determining the reliability of NCP flip chip assembly. Table II indicates that silica filler content has significant effect on the $\alpha 1, \alpha 2, \mathrm{~T}_{\mathrm{g}}$, and modulus. From DMA and TMA results, higher content of silica filler is desirable for the reliability improvement of NCP flip chip assembly.

4) Viscosity and Thixotropy: The rheological analysis was performed to evaluate viscosity of NCP composites. At room temperature, apparent viscosity increased generally as silica 


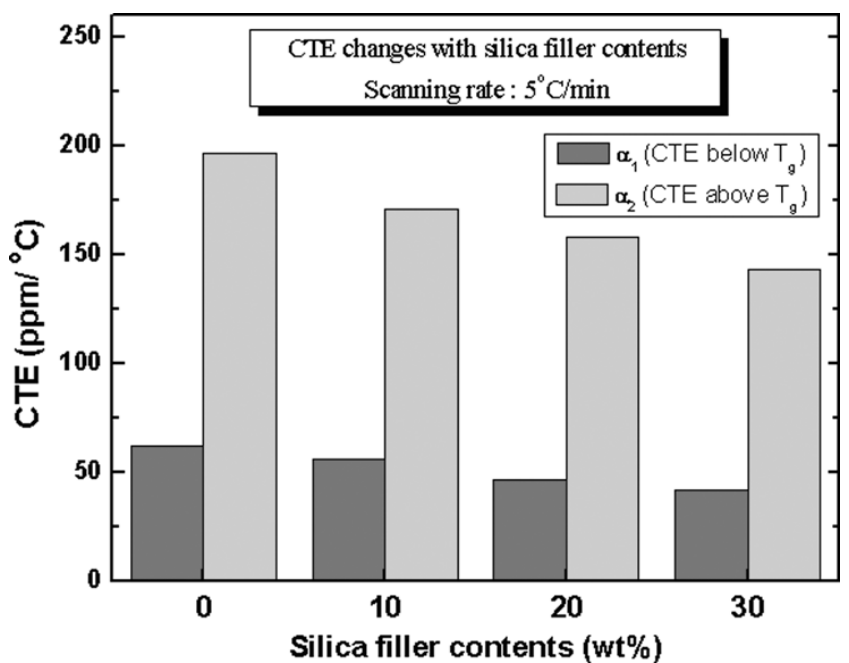

Fig. 5. CTE changes with various silica filler content.

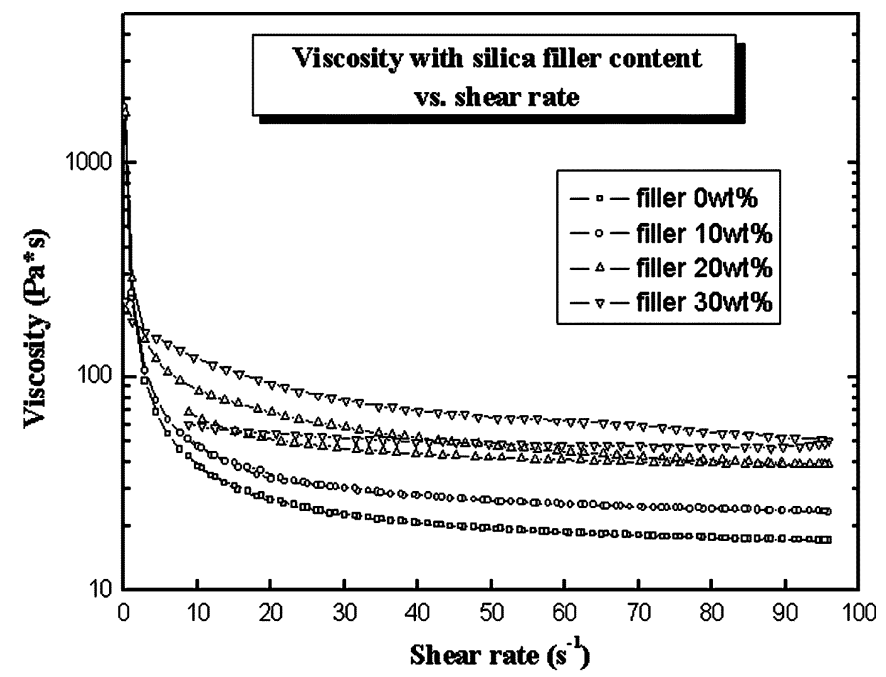

(a)

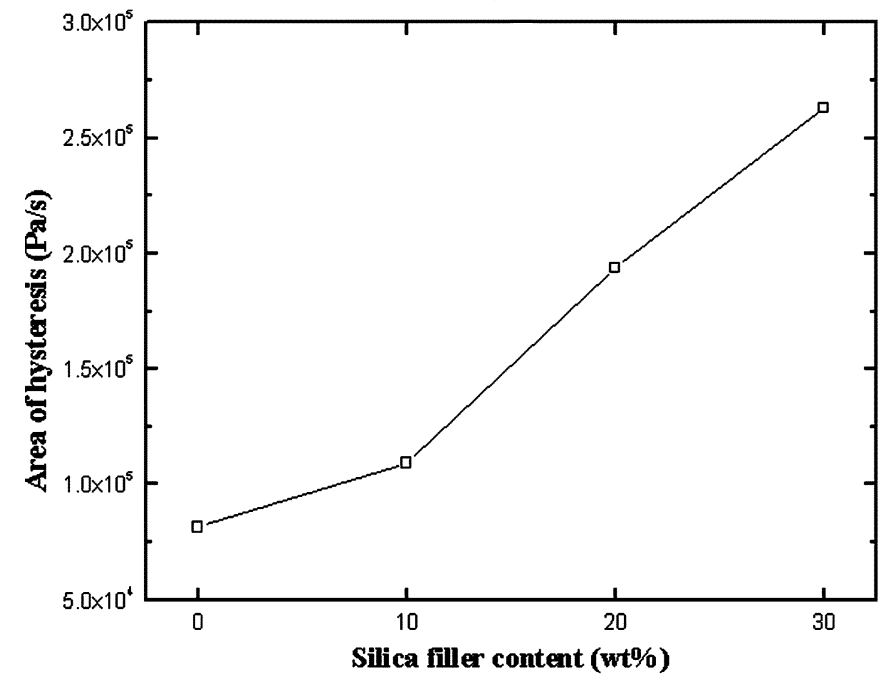

(b)

Fig. 6. (a) Viscosity with silica filler content versus shear rate and (b) area of hysteresis as a function of silica filler content.

filler content increased as shown in Fig. 6. Viscosity decreased as shear rate increased for one sample. And thixotropy increased as silica filler content increased. Because silica fillers act as an

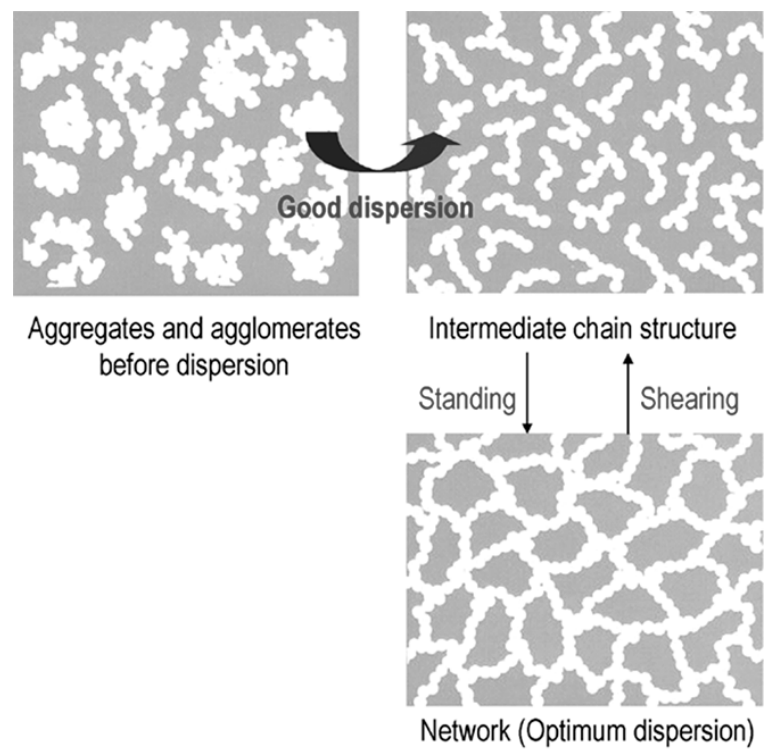

Fig. 7. Model of levels of silica network formation as a function of level shearing during mixing.

obstacle to make fluids difficult to flow, more stress is needed to flow as silica filler content increases. Thixotropy can be qualitatively known by the area of hysteresis in shear rate versus shear stress curve. As silica filler content increased, the area of hysteresis increased. The result can be understood by a model as shown in Fig. 7. The increase in thixotropy with silica filler content is due to van der Waals force among particles. The particles form network structure at stand-by state and the network results in increase in viscosity. If shear force is applied to the mixtures, the shear force breaks down the network structure. This results in lowering in viscosity. Higher filler content is preferable to reduce CTE because of thermomechanical reason. Therefore, in rheological point of view, excess silica fillers make to high viscosity resulting in worse dispersion.

\section{B. Effects of Diluent on NCP Properties}

Dispensing problem due to high viscosity can be solved by using diluents (monomers). Effects of diluents on NCP properties were described at the same silica filler content, $30 \mathrm{wt} \%$.

1) DMA Result: Fig. 8 shows the variation of the storage modulus $\left(E^{\prime}\right)$ and loss $\operatorname{tangent}(\tan \delta)$ of NCPs with different diluent content as a function of holding temperatures. The storage modulus of cured NCPs at room temperature decreased. And maximum value of $\tan \delta$ decreased as diluent content increased, because diluent has linear molecular structure. Molecular chain mobility increases, as diluent content increases. This phenomenon makes cured NCPs softer. When diluent was added $8.0 \mathrm{wt} \%$, glass transition temperature decreased down to about $65{ }^{\circ} \mathrm{C}$. Excessive amount of diluent can cause a serious detrimental effect on thermomechanical properties of NCPs, especially $\mathrm{T}_{\mathrm{g}}$.

2) TMA Result: Fig. 9 shows CTE values of NCPs with various diluent contents. In microscopic view, shorter chains of polymer molecules can move more easily than longer chains as discussed in Section III-B-1. 


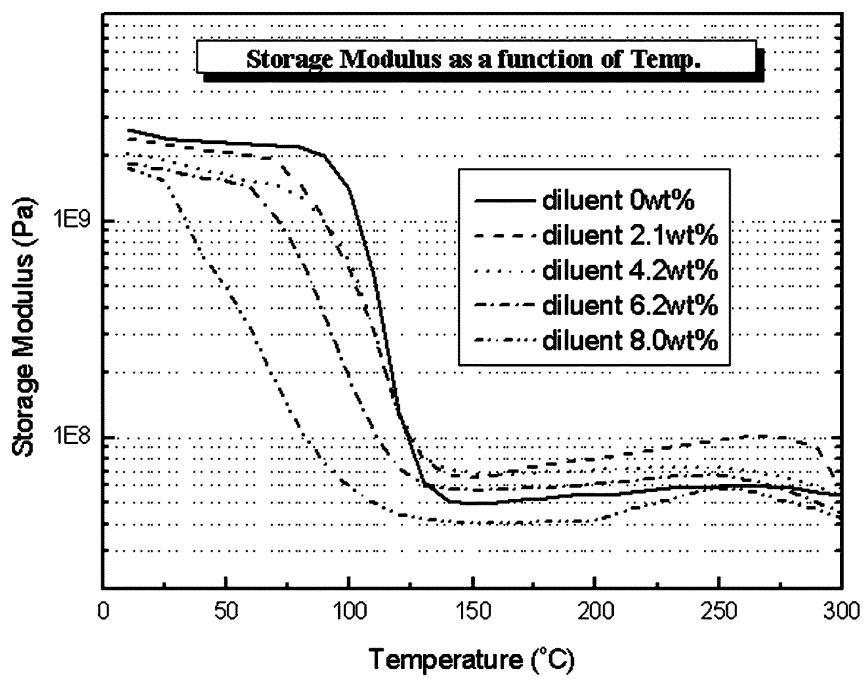

(a)

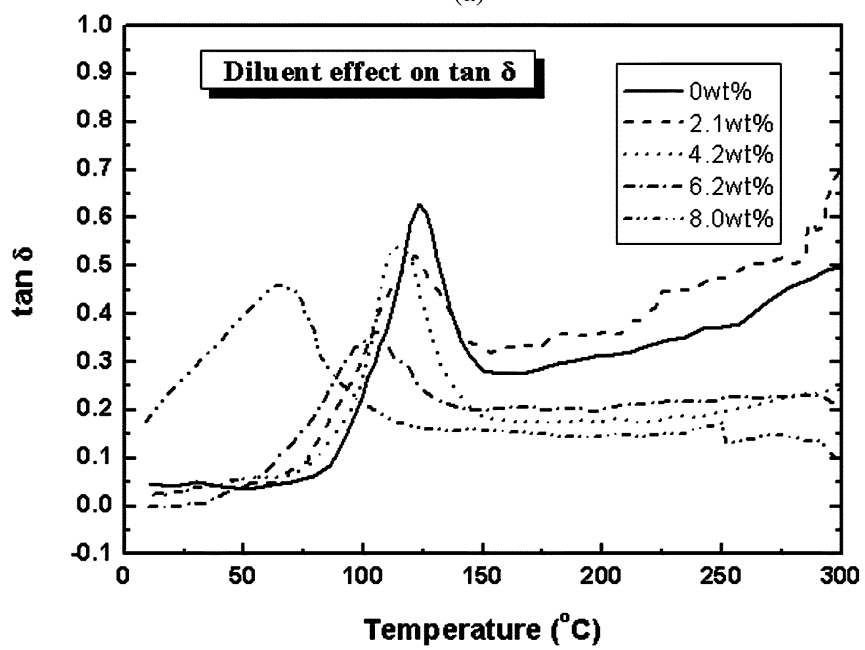

(b)

Fig. 8. (a) Storage modulus curves and (b) $\tan \delta$ curves of NCPs with different diluent content.

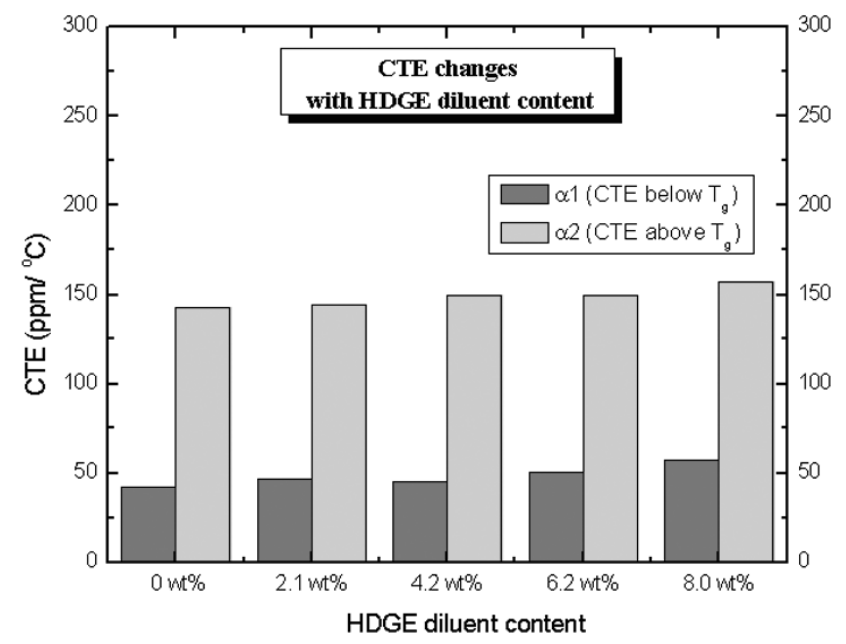

Fig. 9. CTE changes of NCPs as a function of diluent amount.

3) Viscosity and Thixotropy: The main purpose of adding diluents is to improve dispensability by lowering viscosity. Fig. 10 shows viscosity and thixotropic index changes as a function of diluent content. Viscosity decreased clearly as

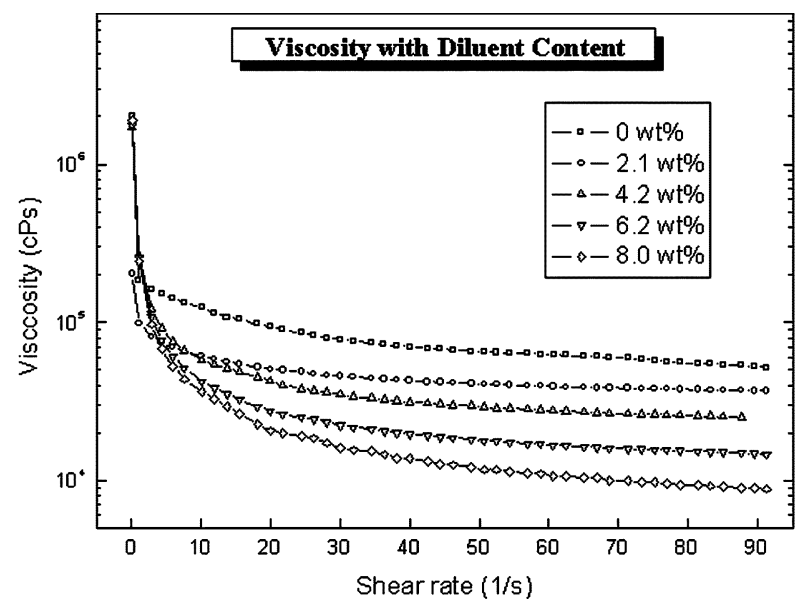

(a)

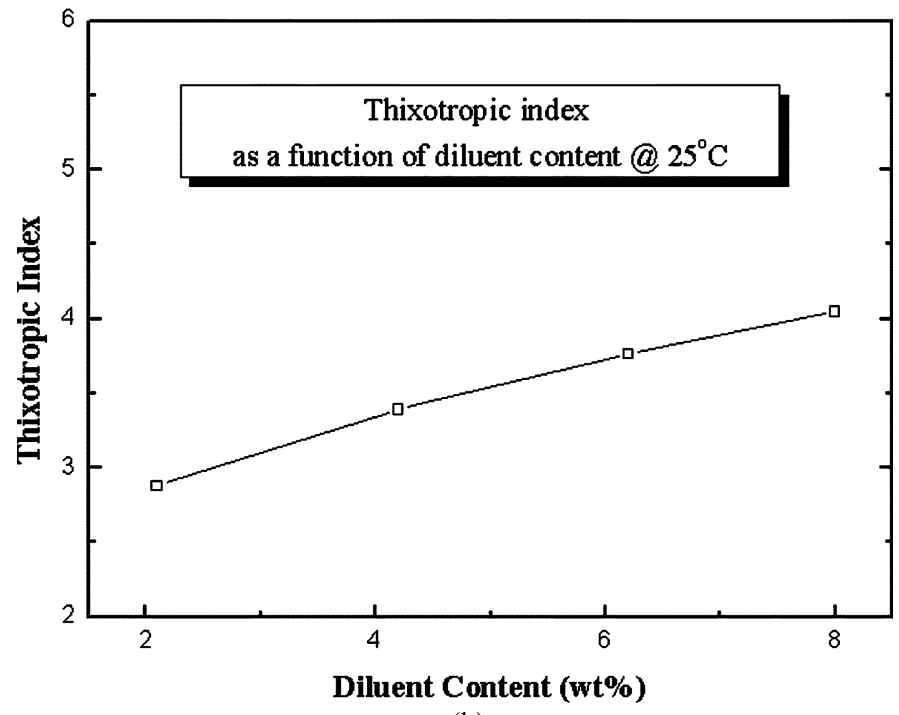

(b)

Fig. 10. (a) Viscosity with various diluent content versus shear rate and (b) thixotropic index as a function of diluent content.

diluent content increased. In addition, thixotropic index increased from 2.8 to 4.1 . It is presumably due to particles can move more easily in matrix and particle interactions increases relatively higher as diluent content increases. Changes of thermomechanical properties and dispensability by adding diluents are contrary to each other. Therefore, tradeoff is needed in optimizing diluent amounts.

\section{Thermal Cycle Reliability}

Fig. 11 shows cumulative distributions of connection resistance changes of NCP flip chip during $-55^{\circ} \mathrm{C}(15 \mathrm{~min})$ $\sim 125^{\circ} \mathrm{C}(15 \mathrm{~min})$ thermal cycling condition. For NCP-A (with no silica filler and diluent) flip chip assembly, first fail occurred after 2008 cycles. Also for NCP-C (with silica filler and diluent) flip chip assembly, first fail occurred after 1466 cycles. However, NCP-B (with silica filler and no diluent) flip chip assembly passed 3000 cycles without fail. Failure accelerated more rapidly for NCP-A than two other samples. These results of the thermal cycling test indicate that thermomechanical properties of NCP composites have noticeable effects on the reliability of NCP flip chip assembly on an organic substrate. The higher content of silica filler in NCPs causes lower CTE 


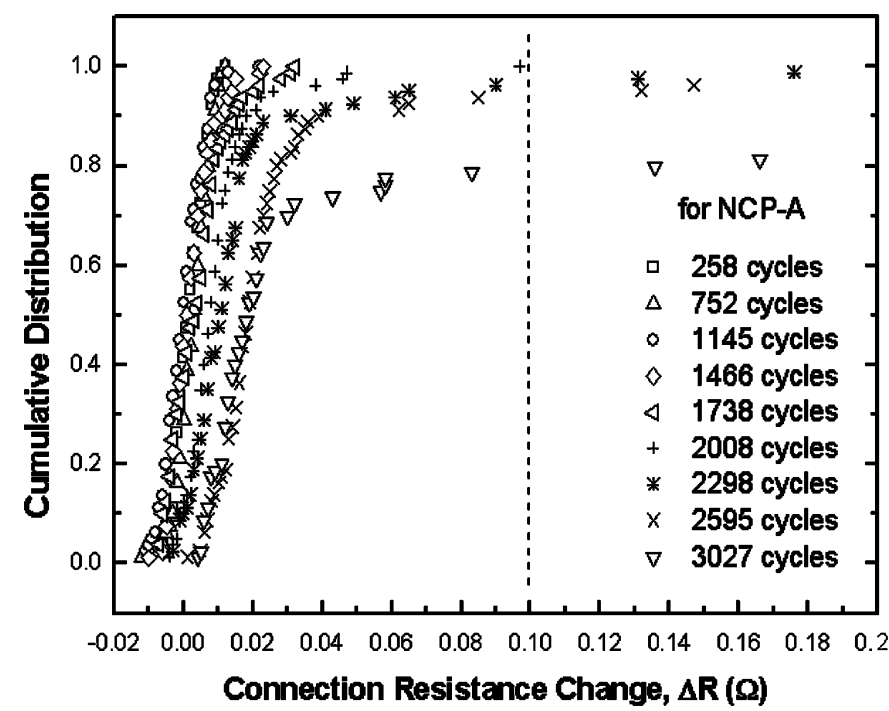

(a)

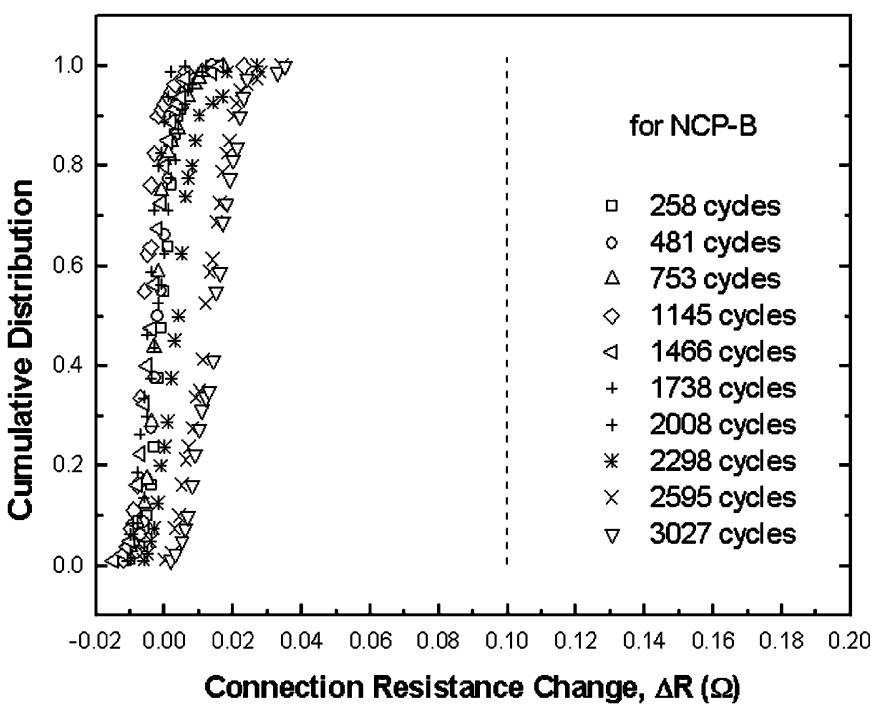

(b)

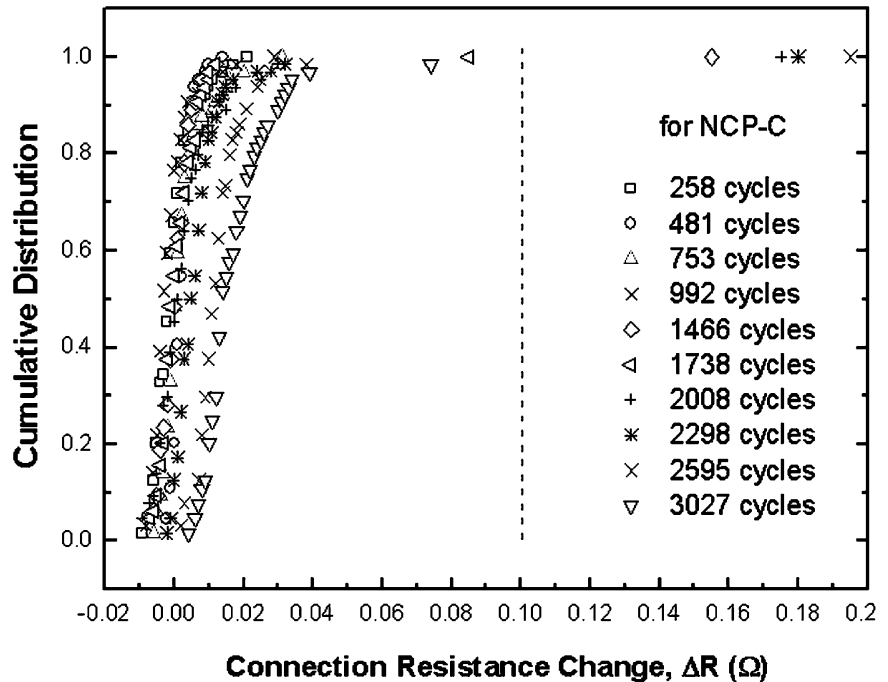

(c)

Fig. 11. Cumulative distributions of connection resistance changes for flip chip assembly using (a) NCP-A, (b) NCP-B, and (c) NCP-C in thermal cycling test.

and higher storage modulus resulting in a higher reliability of NCP flip chip assembly on an organic substrate during thermal cycling test [4].

It was already reported that as the induced shear strain in adhesive layer reduced, thermal cycling reliability of flip-chip assembly was improved. This is due to the more rigid mechanical constraints between the chip and the board [5]. Accordingly, the modification of mechanical properties due to the silica filler addition results in improvement of thermal cycling reliability [4].

Induced shear strain was calculated for used three NCPs. One-dimensional analytical solution of stress and strain in a trilayer composite structure which is allowed to bent freely was published by Suhir [6]. Schematic diagram of trilayer structure was shown in Fig. 12. From Suhir's model, the shear deformation of the second layer, in this case the NCP composite, can be explained as [7]

$$
\gamma_{\mathrm{zx}}(x)=k \frac{2 \Delta \alpha \Delta T \sin h k x}{3 G_{2} \lambda \cos h k l} .
$$

The parameters are defined as follows.

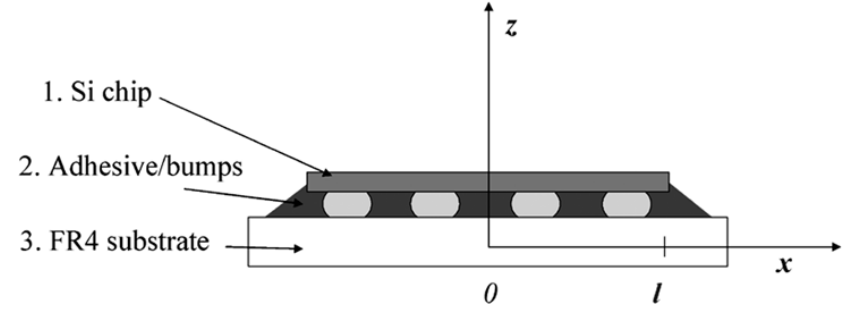

Fig. 12. Schematic diagram of a trilayer structure flip-chip on a board.

$\begin{array}{ll}x & \text { Distance from chip center. } \\ 2 l & \text { Chip length. } \\ t_{i} & \text { Thickness of layer } i . \\ E_{i} & \text { Elastic modulus of layer } i . \\ v_{i} & \text { Poisson ratio of layer } i . \\ G_{i}=E_{i} / 2\left(1+v_{i}\right) & \text { Shear modulus of layer } i . \\ D_{i}=E_{i} t_{i}^{3} / 12\left(1-v_{i}^{2}\right) & \text { Flexural rigidity of layer } i . \\ D=D_{1}+D_{2}+D_{3} & \text { Flexural rigidity. } \\ t=t_{1}+t_{2}+t_{3} & \text { Assembly thickness. } \\ \lambda=\frac{\left(1-v_{1}\right)}{E_{1} t_{1}}+\frac{\left(1-v_{3}\right)}{E_{3} t_{3}}+\frac{t^{2}}{4 D} & \text { Axial compliance. }\end{array}$




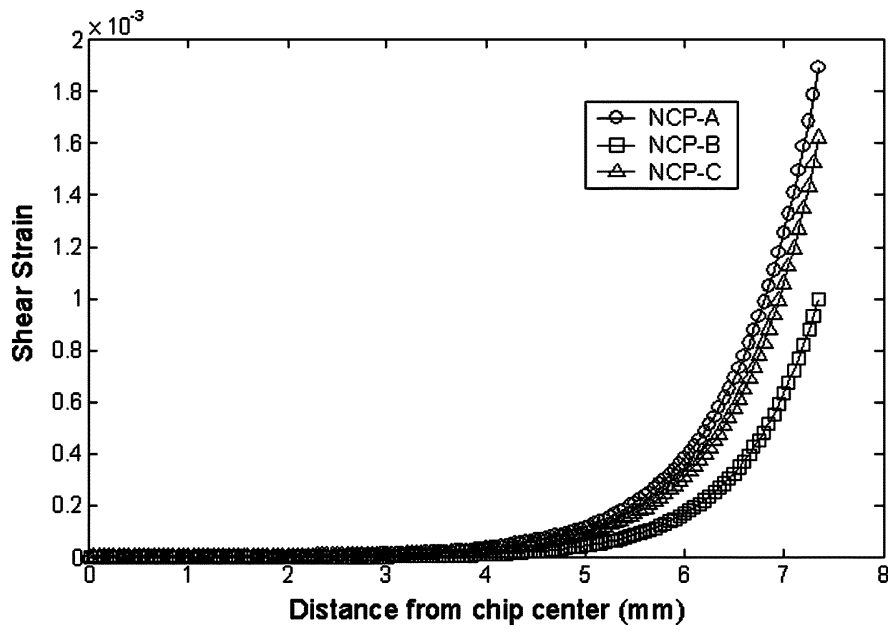

Fig. 13. Calculated shear strain for 3 NCPs.

TABLE III

SUMMARY OF PROPERTIES OF NCPS USED IN SHEAR STRAIN ANALYSIS

\begin{tabular}{r|c|c|c|c|c|c}
\hline & Chip & NCP-A & NCP-B & NCP-C & $\begin{array}{c}\text { FR-4 } \\
\text { Substrate }\end{array}$ \\
\hline \multicolumn{2}{l|}{ Thickness $(\mu \mathrm{m})$} & 700 & 60 & 60 & 60 & 1200 \\
\hline $\mathrm{C} \begin{array}{c}\mathrm{CTE} \\
\left(\mathrm{ppm} /{ }^{\circ} \mathrm{C}\right)\end{array}$ & $\alpha 1$ & 2.8 & 62 & 42 & 45 & 15.8 \\
\cline { 2 - 7 } & $\alpha 2$ & - & 197 & 143 & 150 & 20.0 \\
\hline \multicolumn{2}{l|}{ Modulus (GPa) } & 160 & 1.57 & 2.41 & 1.74 & 17.2 \\
\hline \multicolumn{2}{l}{ Poisson's ratio } & 0.27 & 0.34 & 0.34 & 0.34 & 0.15 \\
\hline \multicolumn{2}{l}{$\begin{array}{l}\text { Glass transition } \\
\text { temperature }\left({ }^{\circ} \mathrm{C}\right)\end{array}$} & - & 119 & 128 & 114 & - \\
\hline
\end{tabular}

$$
\begin{aligned}
& \kappa=\frac{t_{1}}{3 G_{1}}+\frac{2 t_{2}}{3 G_{2}}+\frac{t_{3}}{3 G_{3}} \quad \text { Interfacial compliance. } \\
& k=\sqrt{\lambda / \kappa}
\end{aligned}
$$

Assuming that the stud bumps deform along with the NCP composite layer, (1) can be used as an estimation of the induced shear strain in stud bumps. Calculated shear strain as a function of $x$ was plotted in Fig. 13. Material properties were summarized in Table III for shear strain analysis. Poisson's ratio of $\mathrm{NCP}$ composite was assumed as a typical value for a cured rigid epoxy system, 0.34 [8].

As shown in Fig. 13, calculated shear strain dramatically increased along $x$-axis. It is presumably understood that interconnection resistance increase occurred at chip edge side may be related to the shear strain. The difference in the three shear strain curves is due to the modulus characteristics of each adhesive layer. As shown in previous results, it is understood that high modulus NCP results in small shear strain and results in good $\mathrm{T} / \mathrm{C}$ reliability.

\section{CONCLUSION}

The content of silica filler was the key factor which controls thermomechanical properties of NCPs such as CTE, modulus, and $\mathrm{T}_{\mathrm{g}}$. As the content of silica filler increased, $\mathrm{T}_{\mathrm{g}}$ and storage modulus increased. At the same time, the CTE decreased. However, the content of diluent was the key factor to improve the dispensability of NCPs. As diluent content increased, viscosity decreased and thixotropy increased, but thermomechanical properties such as CTE, modulus, and $\mathrm{T}_{\mathrm{g}}$ were deteriorated. In order to verify relationship between thermomechanical properties of NCPs and flip chip reliability, three kinds of NCPs were compared. NCP-B (with silica filler and no diluent) flip chip assembly could pass 3000 cycles without fail, but NCP-A and NCP-C flip chip could not pass 2000 cycles. Definitely, lower CTE and higher modulus NCP flip chip assembly improved the thermal cycling (T/C) reliability [9]-[19].

For better T/C reliability, high content of silica filler is preferred, unless the viscosity of NCP composite is too high to be dispensed. To obtain the optimum properties of NCPs, trade-off between thermomechanical properties and dispensability is needed.

\section{REFERENCES}

[1] M. J. Yim, Y. D. Jeon, and K. W. Paik, "Flip chip assembly on organic board using anisotropic conductive adhesives/films and nickel/gold bump," in Proc. InterPACK'99, 1999.

[2] R. K. Li, J. Z. Liang, and S. C. Tjong, "Morphology and dynamic mechanical properties of glass beads filled low density polyethylene composites," J. Mater. Process. Technol., vol. 79, pp. 59-65, 1998.

[3] B. Jauregui-Beloqui, J. C. Fernandez-Garcia, A. C. Orgiles-Barcelo, M. M. Pastor-Blas, and J. M. Martin-Martinez, "Thermoplastic polyurethane-fumed silica composite: influence of the specific surface area of fumed silica on the viscoelastic and adhesion properties," $J$. Adhesion Sci. Technol., vol. 13, no. 6, pp. 695-711, 1999.

[4] M. J. Yim and K. W. Paik, "Effect of nonconducting filler additions on ACA properties and the reliability of ACA flip-chip on organic substrates," IEEE Trans. Comp. Packag. Technol., vol. 24, pp. 24-32, Mar. 2001.

[5] M.-J. Yim, Y.-D. Jeon, and K.-W. Paik, "Reduced thermal strain in flip chip assembly on organic substrate using low CTE anisotropic conductive film," IEEE Trans. Electron. Packag. Manufact., vol. 23, pp. 171-176, July 2000.

[6] E. Suhir, "Die attachment and its influence on thermal stresses in the die and the attachment," in Proc. IEEE/EIA 37th Electronic Components Conf., 1987, pp. 143-148.

[7] J. B. Nysaether, P. Lundstrom, and J. Liu, "Measurement of solder bump lifetime as a function of underfill material properties," IEEE Trans. Comp., Packag., Manufact. Technol. A, vol. 21, pp. 281-287, June 1998

[8] H. Lee and K. Neville, Handbook of Epoxy Resins. New York: McGraw-Hill, 1982, pp. 6-24.

[9] C. A. May and Y. Tanaka, Epoxy Resins. New York: Marcel Dekker, 1973.

[10] Encyclopedia of Polymer Science and Technology. New York: Wiley, 1967, vol. 6, p. 209

[11] B. J. Hunt and M. I. James, Polymer Characterization. Glasgow, U.K.: Blackie, 1993, pp. 178-221.

[12] J. Liu, Conductive Adhesives for Electronics Packaging. New York: Electrochemical Publications, Ltd., 1999, pp. 6-16.

[13] L. Crane, A. Torres-Filho, C. K. Ober, S. Yang, J. Chen, and R. W. Johnson, "Development of reworkable underfills, materials, reliability and processing," IEEE Trans. Comp., Packag., Manufact. Technol. A, vol. 22, pp. 163-167, June 1999.

[14] L. E. Nielsen and R. F. Landel, Mechanical Properties of Polymers and Composites. New York: Marcel Dekker, Inc., 1994, pp. 377-459.

[15] J. Liu and Z. Lai, "Reliability of anisotropically conductive adhesive joints on a flip-chip/FR-4 substrates," J. Electron. Packag., vol. 124, pp. 240-245, 2002.

[16] R. Miessner, R. Aschenbrenner, and H. Reichl, "Correlation of thermomechanical properties of adhesives with reliability of FC interconnections," in Proc. 3rd Int. Conf. Adhesive Joining and Coating Technology in Electronics Manufacturing, , 1998, pp. 299-304.

[17] R. Dudek, H. Berek, T. Fritsch, and B. Michel, "Reliability investigations on conductive adhesive joints with emphasis on the mechanics of the conduction mechanism," IEEE Trans. Comp. Packag. Technol., vol. 23 , pp. 462-469, Sept. 2000.

[18] A. Nagai, K. Takemura, K. Isaka, and O. Watanabe, "Anisotropic conductive adhesive films for flip-chip interconnection onto organic substrates," in Proc. IEMT/IMC Symp., 1998, pp. 353-357. 
[19] J. Liu, "Life time prediction of anisotropic conductive adhesive joints during temperature cycling for electronics interconnect," in Proc. 1st Int. IEEE Conf. Polymers and Adhesives in Microelectronics and Photonics, 2001, pp. 209-212.

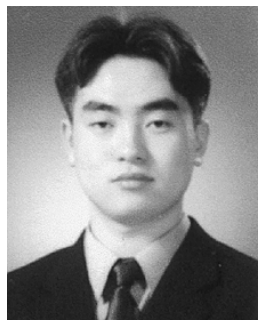

Kyung-Woon Jang received the B.S. and M.S. degrees in materials science and engineering from the Korea Advanced Institute of Science and Technology (KAIST), Daejeon, in 2001 and 2003, respectively, where he is currently pursuing the Ph.D. degree in materials science and engineering.

His research interests are characterization of anisotropic conductive pastes for packaging application and development of polymer/ceramic embedded capacitor pastes.

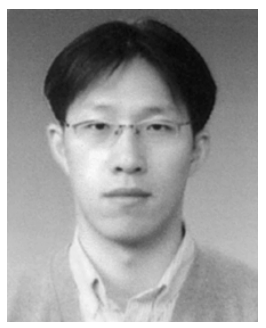

Woon-Seong Kwon received the B.S. and M.S. degrees in materials science and engineering from the Korea Advanced Institute of Science and Technology (KAIST), Daejeon, in 1998 and 2001, respectively, where he is currently pursuing the Ph.D. degree in microelectronic packaging.

His research interests are developing of anisotropic conductive adhesive materials for packaging application, flip-chip using anisotropic conductive adhesives, and its reliability assessment and high frequency electrical characterization.

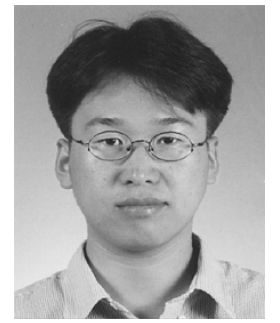

Myung-Jin Yim (S'99-A'01) received the B.S., M.S, and Ph.D. degrees in materials science and engineering from Korea Advanced Institute of Science and Technology (KAIST), Daejeon, in 1995, 1997, and 2001, respectively.

After graduation, he joined the ACF Department, Telephus, Inc., Daejeon, working on the development of ACFs/ACPs for LCD and flip chip packaging. During his Ph.D. course, he was a Visiting Researcher at the IBM T. J. Watson Research Center, Yorktown heights, NY, from September 2000 to February 2001 and was involved in the project on Pb-free solder and intermetallic compound study. His research interests are developing and researching of conductive adhesive materials for display and semiconductor packaging application, flip-chip using anisotropic conductive adhesive and its mechanical and electrical characterization.

Dr. Yim is a Member of the IEEE CPMT Society.

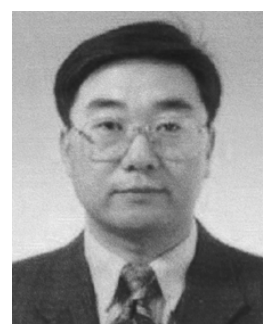

Kyung-Wook Paik (M'95) received the B.Sc. degree in metallurgical engineering from Seoul National University, Seoul, Korea, in 1979, the M.Sc. degree from the Korea Advanced Institute of Science and Technology (KAIST), Daejeon, in 1981, and the $\mathrm{Ph} . \mathrm{D}$. degree in materials science and engineering from Cornell University, Ithaca, NY, in 1989.

From 1982 to 1985, he was with KAIST, Seoul, as a Research Scientist and was responsible for various materials development such as gold bonding wire and nonferrous alloys. After receiving the Ph.D. degree, he worked at the General Electric Corporate Research and Development from 1989 to 1995 , where he was involved with the R\&D of materials and processes of GE high density interconnect (HDI) multichip module technology and power I/C packaging as a member of Senior Technical Staff. After he joined KAIST in 1995, he has been with the Department of Materials Science and Engineering as an Associate Professor. He is currently working in the area of MCM, flip chip, MEMS, and display packaging. He visited the Packaging Research Center, Georgia Institute of Technology, Atlanta, as a Visiting Professor from March 1999 to February 2000, and was involved in the educational and integrated passives research programs. He has published more than 60 technical papers in the area of electronic packaging and currently holds 14 U.S. patents and has four U.S. patents pending.

Dr. Paik is a member of IMAPS and the Chairman of the Korean IEEE-CPMT chapter. 